\title{
The analysis of industrial robot - external axes system movements with the use of virtual off-line programming
}

Keywords:

welding positioners;

motion tracks;

external axis of the robot;

off-line programming

\begin{abstract}
Both, positioners as well as robot motion tracks to be integrated with industrial robots as their external axes should fulfil high work requirements. The toughness structure of such systems resulted in high carrying capacity and repeatability of positioning must be compatible with the system kinematic ability to be used in typical technological application. During such systems design process its functional verification can be done with the use of virtual off-line programming. The already complemented in PPU ZAP Robotyka in Ostrów Wielkopolski research methodic as well as results of analysis performed of newly developed manipulating machines as external axes of industrial robots.
\end{abstract}

\section{Introduction}

Comprehensive development and preparation for the industrial implementation of new types of manipulators, with the assurance of the highest quality and performance parameters and at a competitive price, requires conducting comprehensive research and analysis, supported by IT systems [2,16]:

- Computer Aided Design (CAD);

- mathematical (numerical) computer modeling - FEM strength (Finite Element Method);

- kinematic analysis;

- motion simulations, e.g. in an off-line virtual programming environment.

Nowadays, the design process (modeling, construction record) is increasingly being carried out from the beginning on a three-dimensional model, allowing free analysis of structures from any perspective, taking into account individual components and even simulated traffic. Of course, there is a possibility of cooperation between CAD systems - graphic editors and programs for FEM strength calculations and CAM systems (Computer Aided Manufacturing), including off-line simulators, thanks to fixed standards of graphic formats, e.g. DXF, IGES or STEP. Thanks to this, it is possible to continuously iterate between these systems, until getting the result corresponding to the adopted assumptions. The scope of design described in the CAD/CAM/FEM systems is shown schematically in Figure 1.

The final stage of modeling and verification of CAD models of new manipulator designs may be the motion simulation of their work in a virtual working environment. For this purpose, computer systems for off-line programming of robots and robotic stations can be used, included in simulation methods (off-line simulations).

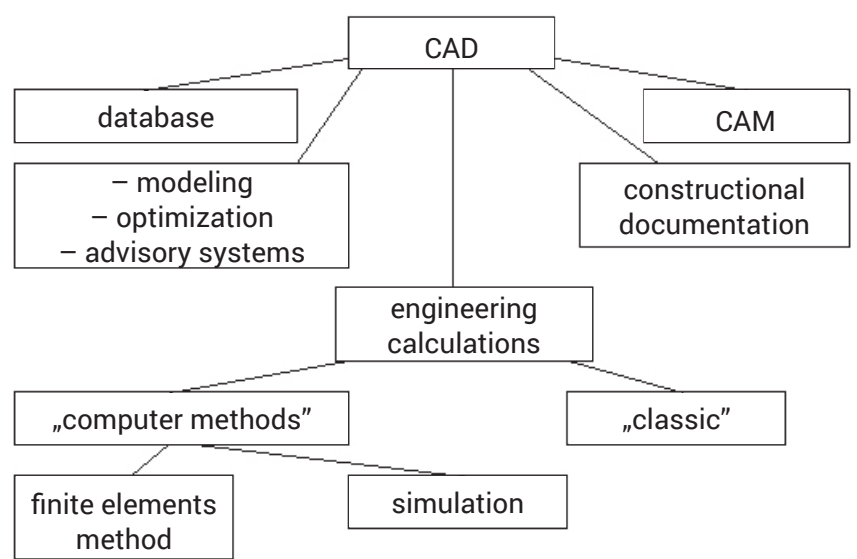

Fig. 1. The scope of computer aided design CAD [16]

dr inż. Paweł Cegielski; dr hab. inż. Dariusz Golański, prof. PW; dr inż. Paweł Kołodziejczak; prof. dr hab. inż. Andrzej Kolasa - Warsaw University of Technology;

dr inż. Tadeusz Sarnowski - ZAP Robotics Ostrów Wielkopolski; 
The main purpose of using off-line systems is to simulate and program the motion of the robot and other elements of the position, fully taking into account their kinematics, sometiFEM also the dynamics and the implemented process. Thanks to this, it is possible to check the interaction of individual station elements on the computer screen (in the geometrical and motional range), without the need to build an expensive test bench (Fig. 2).

The advantages for the project in relation to the simulation with the use of the actual robot and installation are clear.

- saving time that would have to be spent on developing and launching a new installation;

- radical reduction of costs and safety during simulation and work verification;

- the ability to detect geometrical errors of the tested external robot axes;

- the possibility of detecting errors in robot motion sequences and cooperating external axes;

- the ability to check, by simulation, the correctness of the robot's interaction with external axes and the concept of a hypothetical production socket.

The specialist nature of off-line simulation systems should be emphasized, which just like FEM systems, require, in addition to access to the appropriate equipment and software, knowledge and skills acquired in the course of a number of studies and completed projects.

\section{Cooperation in the system robot - external axes}

Robotization of production processes, including arc weIding, requires a detailed orientation (angle of position in space) and movement (trajectory on which it moves) of the effector, e.g. MIG/MAG welding electrode holder, and the orientation of the welded structure. The starting point is technologically imposed conditions for the implementation of specific welds (welded nodes), and the main limitation - the manipulative capabilities of the machines and devices used (robot, positioner, track motion), including insufficient degrees of freedom or limited range of their movement.

In contrast to the orientation and trajectory of tool movement, the concept and classification of welding positions took the form of the most formalized, described in the PN-EN standards or the AWS and ASME regulations. Spatial orientation of the welded joint (so-called welding position) will always be a consequence of the spatial position of the entire structure. As a result of a specific position in the space of a multi-element structure, individual welds will often have different welding positions, including those that are unfavorable for obtaining a high quality connection, and even incompatible with requirements of the process.

Spatial parameters related to the orientation and movement of the tool and the welding position are of great importance for the process, they are interdependent with each other and, as a consequence, they must be considered jointly (Fig. 3 and 4) [1,3,1 1].

At robotic arc welding stations, the orientation of the tool (electrode holder) is related to the robot's kinematic system, and the welding position with the positioning device kinematics (welding positioner). In practice of computer calculations, e.g. analysis of the motion of multi-axis manipulators and robots, simple and inverse task of kinematics is solved (simple and inverse transformation) $[1,8,13]$. These calculations allow to check whether specific points in space, e.g. corresponding to the weld trajectory, are possible to achieve or what will be the final position of the effector (electrode holder) for a given robot arm configuration. The limitation will be not only the length of his arm, but most of all the number

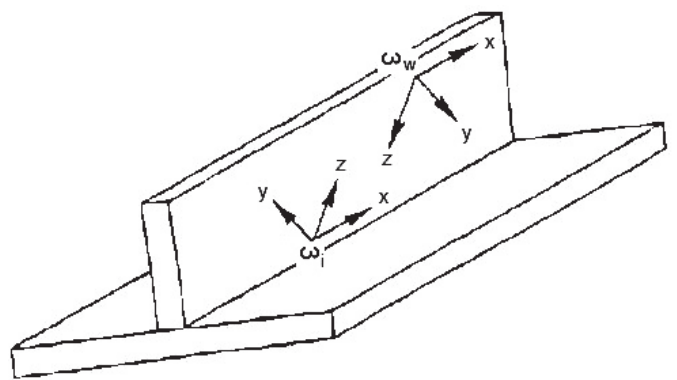

Fig. 3. The definition of welded joint $\left(\omega_{\mathrm{j}}\right)$ and the tool - welding torch $\left(\omega_{w}\right)[1]$

and range of movement of individual axes (degrees of freedom) of the robot and the positioner. Approximately, unless the robot has a specific kinematic chain with six degrees of freedom [10] and a positioner - three (three kinematic pairs of rotation related to the table rotation and tilting) [1], some welding positions and tool orientations will not be possible to achieve.

It should be remembered that changing the welding position is essentially a change in the position of the entire

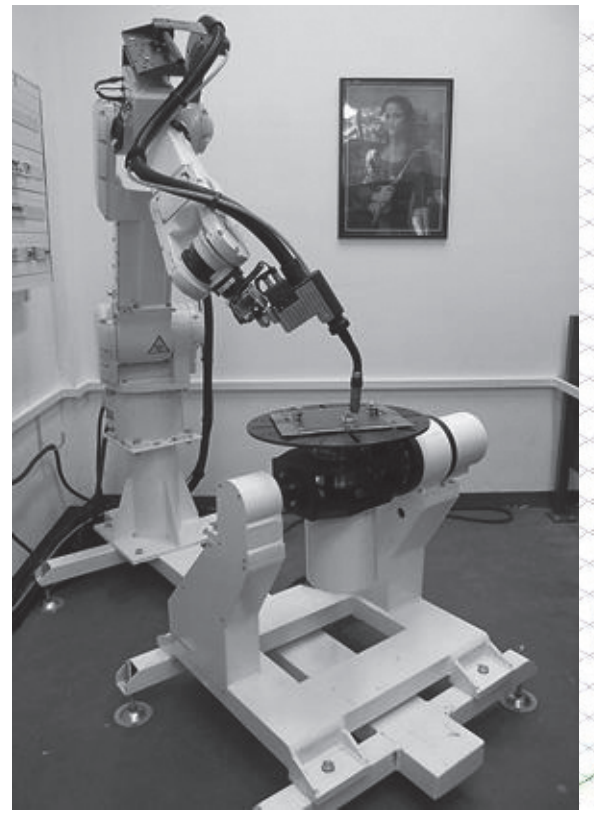

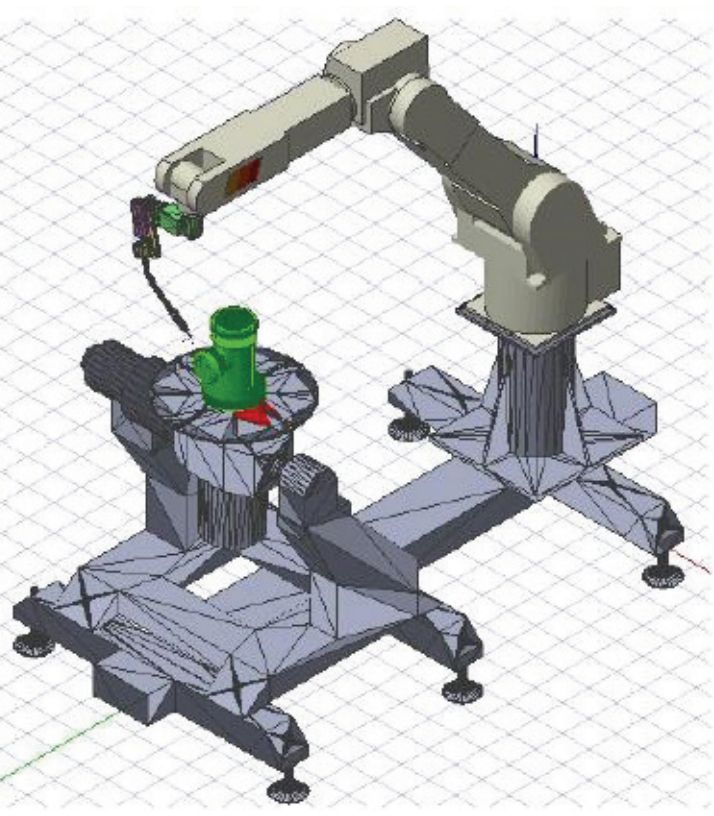

Fig. 2. The overall view of the laboratory stand-up with FA006 Kawasaki industrial robot and its imagine in K-Roset off-line simulation system 
weldment - not always achieving the most technologically convenient position must mean optimal from the point of view of access for the robot and vice versa. The compromise between process requirements and equipment capabilities will always require a series of time-consuming (and costly) tests and physical and technological tests to achieve a satisfactory welding effect. At this point, it can be assumed that the preferred positions are flat PA and horizontal $\mathrm{PB}$, usually obtained at the angle of work of the tool axis [11] (e.g. electrodes) approx. $0 \div 45^{\circ}$.

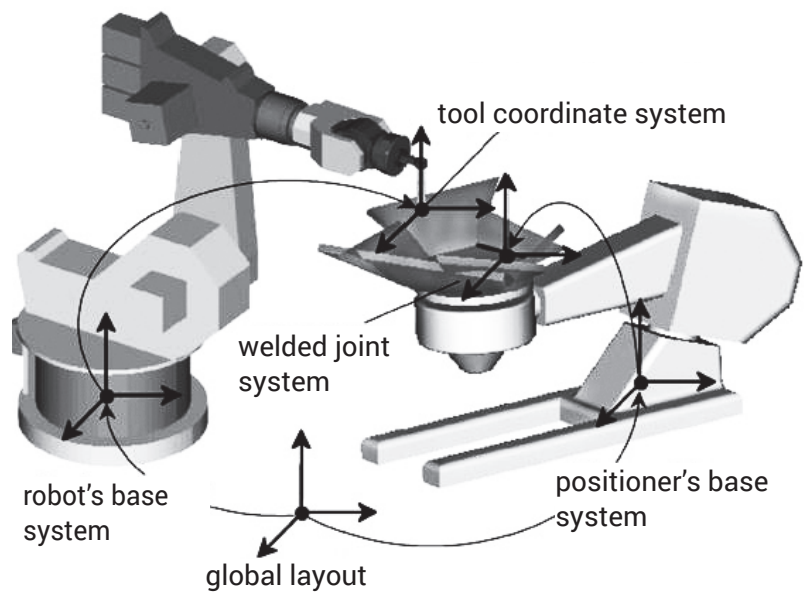

Fig. 4. The coordination system of robotic welding installation components [13]

To optimize robotic welding technology requiring a series of decisions and compromises, overly automated programs and procedures based on simple scheFEM and algorithms cannot be used. In the case of welding CAD/CAM systems, these issues have so far found the most comprehensive practical reference in systems of "manual" off-line robot programming, e.g. ArcWelding PowerPack (ABB), K-Roset (Kawasaki) or ROBGUIDE (Fanuc) [9]. It can also be referred to the discussed problem of motion analysis in the robot system - external axes tested (' $\mathrm{L}$ ' and ' $\mathrm{H}$ ' positioners and motion tracks). The aforementioned mathematical analysis (simple and inverse transformation) will not be justified in the context of the discussed research. On the one hand, the tested manipulators have too simple (obvious) kinematics, e.g. uniaxial track motion, and on the other, standard six-axis robots selected for off-line simulation (and therefore capable of orienting the tool in any way within their working space) will not be subjected to research but they will be a control tool with known kinematics.

The free manipulation of the object mounted on the positioner's table or the tool placed at the end of the robot's arm occurs in a limited space. According to PN-EN ISO 8373: 2001 "Industrial Robots - Terminology", the working area is an area that can be achieved by WRP (Wrist Reference Point - often designated as a P point or a fifth axis point - J5 on Figures 7 and 8) with the addition (in tabular and/or dimensioned sketch) of the rotation or displacement range of each combination of wrists. Because the work space thus determined does not even take into account the maximum range of the robot arm itself (for the Fanuc ArcMate Oib light robot, the $\mathrm{J} 5$ point defining the working space boundary is $100 \mathrm{~mm}$ from the ending flange disc arm - fig. 5), it provides, approximately, information about the useful working range with guaranteed different tool orientation, even on the periphery of the area. According to the same standard, the maximum space is the area that can be swept by moving parts of the robot, defined by the manufacturer, plus the space that is swept by the working element (e.g. electrode holder fixed at the end of the welding arm) and the manipulation object (e.g. held in the gripper - not applicable to the analyzed problem).
In the absence of analogous definitions in relation to positioners, and due to their general similarity to the kinematic structures of typical industrial robots, the maximum space definition can be adapted - the maximum space of the positioner is approximately the area that can be swept by the work table (usually rotary, and often also hung on an articulated mechanism that changes its orientation and position in space) and manipulation object. In addition, due to the non-technological nature of the work of the axis of changing the working positions of double-stand positioners, their maximum space should be determined only for one working side. In the off-line analysis of the robot's interaction with positioners discussed hereinafter, the working and maximum working spaces of the test robot with the maximum positions of positioners will be set.

In the case of cooperation between the robot and the track, two main functional variants are possible: the robot is moved (track setting) to a new position or manipulates the track (working movement of the continuously controlled track), as a result of which its working space undergoes actual magnification. The project assuFEM continuous control of the track running platform, thanks to which it becoFEM possible to operate the transported robot with respect to objects of considerable size and is used, for example, during arc weIding, thermal cutting or the operation of press brakes. In the off-line analysis, only the variant with enlarging the robot's working space through continuously controlled locomotion on the track motion will be considered.

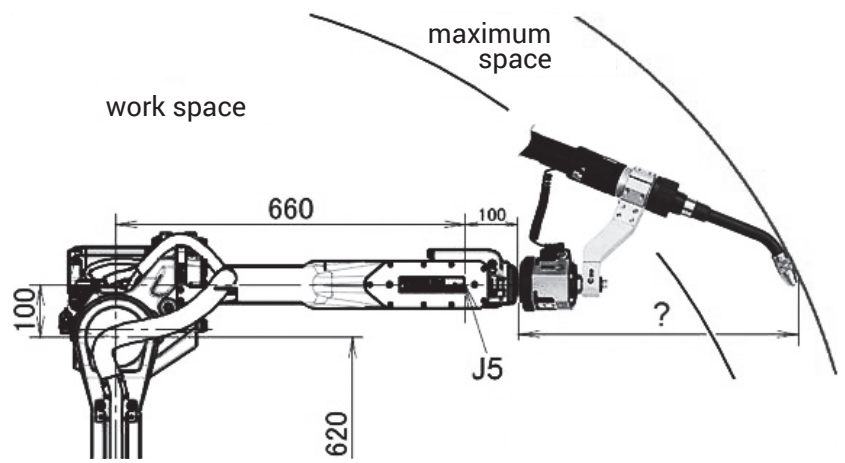

Fig. 5. The Fanuc robot arm 0 and $\mathrm{b}$ with marked $100 \mathrm{~mm}$ distance of point $\mathrm{J} 5$ from end of the arm and boundaries of both working and maximum range of operation

\section{Subject, methodology and scope of research}

The presented analysis concerns the implementation of the stage of research on the development and implementation of three new types of manipulation machines - external robot axes $[4 \div 6]$ in production at ZAP Robotyka in Ostrów Wielkopolski, and are directly related to off-line physical simulation of their CAD construction models. The research covered three series of devices [4,]:

- 'L' type positioners (Fig. 6):

- two sizes - 250 and $500 \mathrm{~kg}$ load capacity,

- for each size, single- and double-stand (two and five controlled axes),

- ' $\mathrm{H}^{\prime}$ type positioners (Figure 6):

- two sizes _ 300 and 1000 kg load capacity (three controlled axes),

- nominal variant of $4.0 \mathrm{~m}$ and shortened spacing between tables up to $2.5 \mathrm{~m}$,

- modular system of motion tracks (Fig. 6) in representative variants selected from among all of those elaborated (listed in table I). 

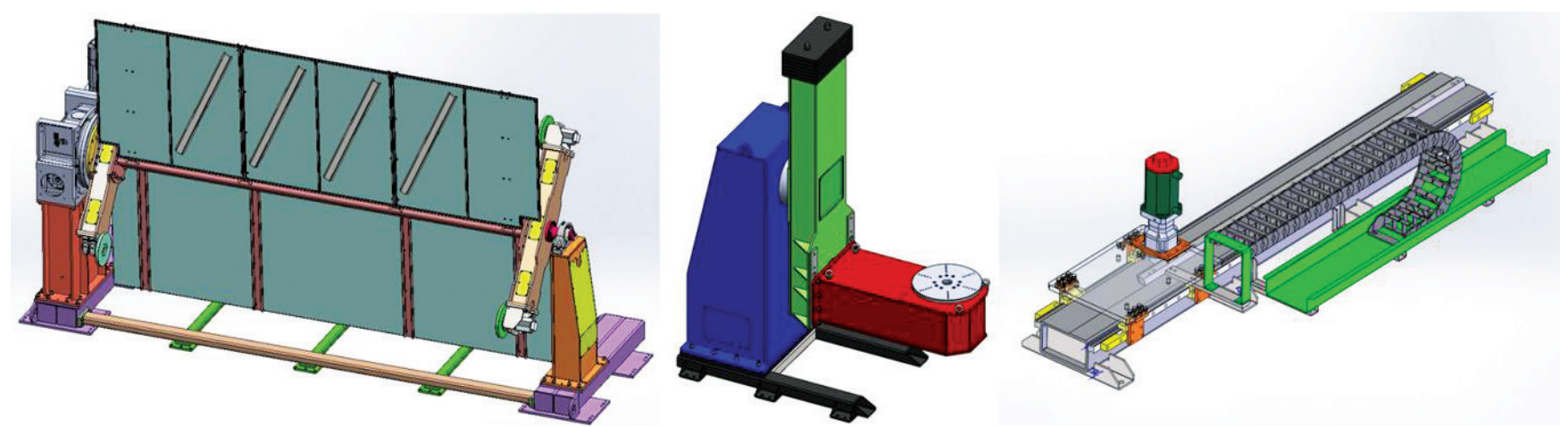

Fig. 6. Newly designed and being tested CAD models of manipulators (from left): H-type, one-stand L-type, floor motion track (some examples)

The main goal of the research was to confirm the ranges of motion of individual axes in accordance with the assumptions for the project (Table II) in interaction with typical weIding robots with a load capacity of $3 \div 20 \mathrm{~kg}$, ensuring maximum filling of the maximum space of each positioner.

- for ' $\mathrm{H}$ ' positioners, one size of the maximum space has been assumed: $1.5 \times 4.0 \mathrm{~m}$ (diameter/length), regardless of the load capacity [5],

- for' 'L' positioners, two sizes of maximum space have been adopted: $1.5 \times 1.5 \times 1.5 \mathrm{~m}$ (for load capacity of $250 \mathrm{~kg}$ ) and $2.0 \times 2.0 \times 2.0 \mathrm{~m}$ (for $500 \mathrm{~kg}$ ) [5].
Table III presents a list of manipulators and welding robots with a load capacity of $3 \div 20 \mathrm{~kg}$, preliminarily selected for off-line tests. The assumption was to use two robots: standard size (action radius $\geq 1400 \mathrm{~mm}$ ) and extended arm (range $\geq 3000 \mathrm{~mm}$ ).

The implemented work schedule, the same for each of the three types of devices, included:

1) development of base models of CAD positioners and motion tracks to the needs and requirements of off-line simulation,

2) creating an off-line simulation environment based on selected industrial robots,

Table I. The motion track options designed within the project

\begin{tabular}{|c|c|c|c|c|}
\hline \multirow{3}{*}{$\begin{array}{l}\text { Length of the track } \\
\text { (module) }\end{array}$} & \multirow{3}{*}{$\begin{array}{l}\text { Robot mounting position and track type } \\
\text { (floor or gate) }\end{array}$} & \multicolumn{3}{|c|}{ Carrying capacity [kg] and number of platforms } \\
\hline & & \multirow{2}{*}{$\begin{array}{c}250 \\
\text { one platform }\end{array}$} & \multicolumn{2}{|c|}{500} \\
\hline & & & one platform & two platforms \\
\hline \multirow{3}{*}{$2.5 \mathrm{~m}$} & Standing (floor track) & yes & yes & - \\
\hline & Wall mounted (gate track) & yes & yes & - \\
\hline & Inverted (gate track) & yes & yes & - \\
\hline \multirow{3}{*}{$5.0 \mathrm{~m}$} & Standing (floor track) & yes & yes & yes \\
\hline & Wall mounted (gate track) & yes & yes & yes \\
\hline & Inverted (gate track) & yes & yes & yes \\
\hline
\end{tabular}

Table II. Number, type and range of movements of axes in each CAD model

\begin{tabular}{|c|c|c|c|c|c|}
\hline \multirow{2}{*}{ Function or parameter } & \multicolumn{2}{|c|}{ 'L' positioners } & \multicolumn{2}{|c|}{ 'H' positioners } & \multirow{2}{*}{$\begin{array}{l}\text { Modular system } \\
\text { of motion tracks }\end{array}$} \\
\hline & size 1 & size 2 & size 1 & size 2 & \\
\hline Number of work tables / driving platforms & \multicolumn{2}{|c|}{1 or 2} & \multicolumn{2}{|c|}{2} & 1 or 2 \\
\hline Drive & \multicolumn{5}{|c|}{ electric (adapted to different control systems) } \\
\hline Total number of controlled axes & \multicolumn{2}{|c|}{$\begin{array}{l}2 \text { - single-stand } \\
5-\text { double-stand }\end{array}$} & \multicolumn{2}{|c|}{3} & 1 \\
\hline Work table rotation / control & \multicolumn{2}{|c|}{$\mathrm{n} \times 360^{\circ} /$ continuous } & \multicolumn{2}{|c|}{$\mathrm{n} \times 360^{\circ} /$ continuous } & - \\
\hline Rotation of the 'L' arm / control & \multicolumn{2}{|c|}{$\mathrm{n} \times 360^{\circ} /$ continuous } & \multicolumn{2}{|c|}{-} & - \\
\hline Rotation of the positions change / control & \multicolumn{2}{|c|}{$2 \times 180^{\circ} /$ discreet } & \multicolumn{2}{|c|}{$2 \times 180^{\circ} /$ discreet } & - \\
\hline Passage of the robot platform / control & - & - & - & - & $\begin{array}{c}\text { linear/ } \\
\text { continuous }\end{array}$ \\
\hline
\end{tabular}


Table III. The set of welding robot and type of manipulator systems being used in off-line simulation ( $\mathrm{M}-$ of standard dimensions, $\mathrm{L}-$ with elongated arm)

\begin{tabular}{|c|c|c|c|c|c|c|c|c|c|c|c|}
\hline & & \multicolumn{2}{|c|}{ 'L' positioners } & \multicolumn{2}{|c|}{ 'H' positioners } & \multicolumn{6}{|c|}{$\begin{array}{c}\text { Motion tracks - robot position: S - standing, } \\
\text { W - wall mounted, I - inverted }\end{array}$} \\
\hline & & \multirow{2}{*}{ size 1} & \multirow{2}{*}{ size 2} & \multirow{2}{*}{ size 1} & \multirow{2}{*}{ size 2} & \multicolumn{3}{|c|}{$2.5 \mathrm{~m}$} & \multicolumn{3}{|c|}{$5.0 \mathrm{~m}$} \\
\hline & & & & & & $\mathrm{s}$ & w & $\mathbf{I}$ & $\mathrm{s}$ & w & $\mathbf{I}$ \\
\hline \multicolumn{2}{|c|}{ Only robot } & \multicolumn{4}{|c|}{$M, L$} & \multicolumn{6}{|c|}{$\mathrm{M}$} \\
\hline \multirow{2}{*}{ 'L' positioners } & size 1 & - & - & - & - & \multicolumn{3}{|c|}{$M, L$} & - & - & - \\
\hline & size 2 & - & - & - & - & \multicolumn{3}{|c|}{$M, L$} & - & - & - \\
\hline \multirow{2}{*}{ 'H' positioners } & size 1 & - & - & - & - & \multicolumn{3}{|c|}{$M, L$} & \multicolumn{3}{|c|}{$M, L$} \\
\hline & size 2 & - & - & - & - & \multicolumn{3}{|c|}{$M, L$} & \multicolumn{3}{|c|}{$M, L$} \\
\hline
\end{tabular}

3) research and simulations in accordance with the assumed methodology,

4) final verification of models.

As a result of discussions and literature analyzes of cooperation in the system robot - external axes, a detailed methodology of research and simulation in the off-line environment was formulated in relation to the developed devices:

1) checking the correctness of interaction between robot workspace and base models of positioners and motion tracks - static geometry tests (without programmed motion):

a. visual verification of motion ranges of individual axes of tested devices in accordance with the assumptions for the project - Table II,

b. compilation (in accordance with table III) of robots and manipulators - visual analysis and visual verification of the basic operating range by placing the robot's working space on the maximum space of the tested positioner (for double-stand analysis only applies to one side), without and with the track motion (magnifying the working space of the robot),

c. for configurations and settings obtained in point $1 \mathrm{~b}-\mathrm{vi}-$ sual verification of the effective operating range (ability to cooperate) with the vertical orientation (in selected points of the maximum position of the tested positioner) of the electrode axis of a typical MIG/MAG electrode holder mounted at the end of the robot arm.

2) simulation for errors in robot motion sequences and base models - movement tests:

a. for configurations and settings obtained in point $1 \mathrm{c}-$ motion verification (coordinated movement of the robot and tested manipulators) of the effective operating range (ability to cooperate) with the vertical orientation (in selected points of the maximum position of the tested positioner) of the electrode axis of a typical MIG/MAG electrode holder mounted on the end of the robot arm,

b. for configurations and settings obtained in point 1c - during motion of a coordinated robot and manipulators investigated, motion analysis of collision hazards with structural elements of positioners, i.a. double-stand versions during side changes,

c. for configurations and settings obtained in point $2 a-d u-$ ring the movement of the coordinated robot and the manipulators under investigation, analysis and verification of ensuring a continuous path between selected points, in search of errors in motion sequences, lack of range, etc.

A specialized tool for programming and off-line simulation of industrial robots - the ROBGUIDE (Fanuc) package was used for the research. It is an integrated environment for modeling robotic production stations and simulating the work of robots and machines integrated with them.

\section{Development of CAD models for simulation}

Off-line analyzes were conducted based on 3D CAD models imported to the ROBGUIDE simulation environment directly from CAD editor graphic files. It was necessary to provide the possibility of simulating the movement of all axes of manipulation in the assumed range, analogously to the real devices (Table II). For this purpose, functional blocks corresponding to individual structural units had to be distinguished, e.g. a body - a rotating arm - a working table for ' $L$ ' positioners, and then linked in an off-line environment by inserting drive units. This way, the possibility of manual and programmed movement of individual axes was obtained.

\section{Creating an off-line simulation environment}

The tested manipulators - ' $\mathrm{L}$ ' and ' $\mathrm{H}$ ' positioners and motion tracks will be used in various production processes, however, they will most often be used during arc welding. Welding tasks are also the biggest physical challenge, i.a. due to the necessity of lapping with the effector mounted on the robot's arm to any place, including very remote places on the manipulated structure with the provision of spatial orientation imposed by technological requirements. In addition, developed manipulators are designed for medium-sized objects (whose size in at least one direction exceeds $1 \mathrm{~m}$ and is not greater than a few meters), inherently requiring the use of the largest possible robots. Therefore, the following environmental conditions of off-line simulation were adopted:

- simulation tool - off-line package ROBGUIDE (Fanuc),

- welding industrial robots with a load capacity of $3 \div 20 \mathrm{~kg}$,

- representative units with six axes in the anthropomorphic system were selected, available in the ROBGUIDE environment:

- robot with a standard or medium arm length (operating radius $\geq 1400 \mathrm{~mm})$, e.g. Fanuc ArcMate 100iC/7L (7 kg, $+/-0.03 \mathrm{~mm}$, radius $1633 \mathrm{~mm}$ ) or ArcMate 100ic/12 (12 kg, $+/-0.03 \mathrm{~mm}$, radius $1420 \mathrm{~mm}$, Fig. 7),

- robot with an extended arm (operating radius $\geq 3000 \mathrm{~mm}$ ), e.g. Fanuc ArcMate $710 \mathrm{iC} / 20 \mathrm{~L}(20 \mathrm{~kg},+/-0.06 \mathrm{~mm}$, radius $3110 \mathrm{~mm})$ or $\mathrm{M}-710 \mathrm{iC} / 12 \mathrm{~L}(12 \mathrm{~kg},+/-0.09 \mathrm{~mm}$, radius $3123 \mathrm{~mm}$, Fig. 8),

- simulated process - arc welding and related processes,

- robot effector - a typical MIG / MAG electrode holder taken from the off-line program database.

As mentioned before, in the case of cooperation of a robot with objects manipulated via positioners, both without and with motion tracks, it is important not only to reach the points in the working space of the positioner, e.g. with the welding 


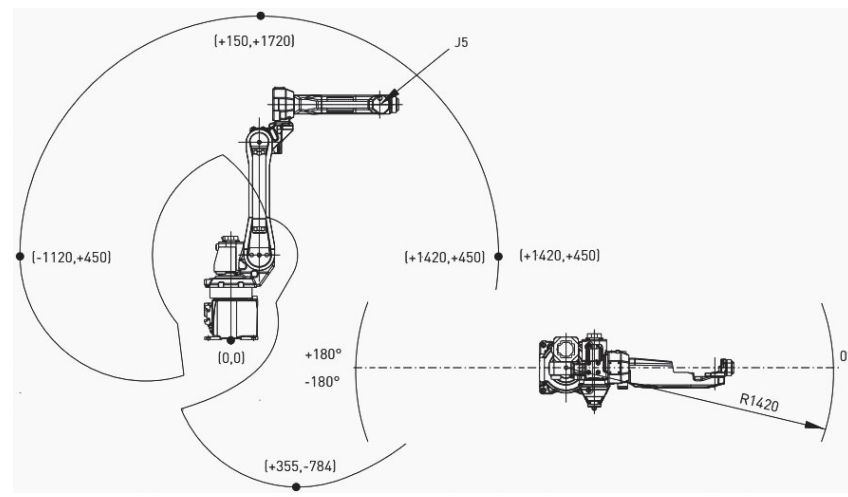

Fig. 7. The outline of working range of operation of ArcMate 100iC/12 robot manipulator and point $\mathrm{J} 5$ of fifth axe (Fanuc)

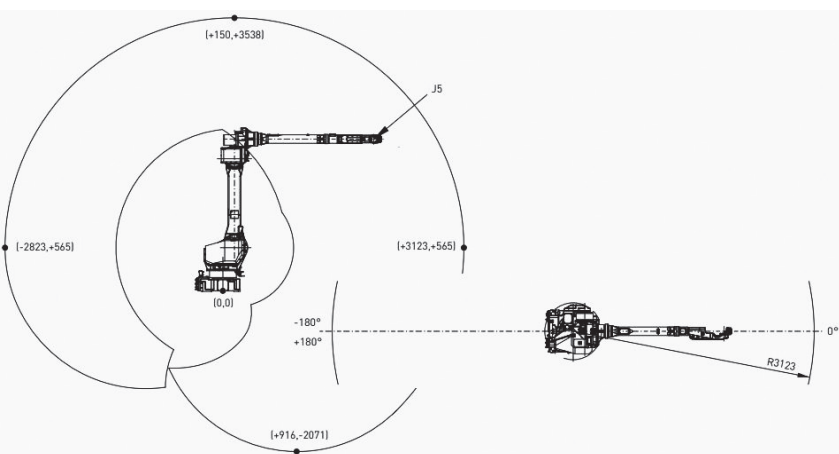

Fig. 8. The outline of working range of operation of ArcMate $710 \mathrm{iC} / 12$ robot manipulator and point $\mathrm{J} 5$ of fifth axe (Fanuc)

electrode holder, but also the ability to obtain in these points required by the orientation of the electrode and the execution of programmed motion between them. Therefore, it was necessary to develop test models of objects representative of typical welded constructions manipulated by ' $\mathrm{H}$ ' and ' $\mathrm{L}$ ' positioners. In contrast to, for example, chip processes, for which objects such as a shield, shaft or body are classified, the variety of forms and dimensions of welded products makes it difficult to clearly divide. In the literature, there are few attempts to extract objects, e.g. a box, angle or pipe $[7,12]$. With regard to the project, two objects were initially proposed (Fig. 9) - a spatial frame (for 'L' and ' $\mathrm{H}$ ' models) and a pipe with stub pipes (for ' $\mathrm{H}^{\prime}$ ), with main dimensions adapted to the maximum spaces of individual models (table IV).

Table IV. The set of work structure model dimensions being manipulated

\begin{tabular}{|c|c|c|c|c|c|c|}
\hline \multirow{2}{*}{} & \multicolumn{6}{|c|}{ Dimension [mm] } \\
\cline { 2 - 7 } & 530 & 1200 & 1500 & 2000 & 2500 & 4000 \\
\hline L1 & & & + & + & + & + \\
\hline L2 & & & & & + & + \\
\hline W & & + & + & + & & \\
\hline H & + & & + & + & & \\
\hline
\end{tabular}

Subsequently, a universal simulation environment was created in the form of a scene with the possibility of inserting the tested model / CAD models without and with the selected robot. The element of the off-line scene is the determination of the global Cartesian coordinate system, which is the reference for inserted objects and the movement of individual axes (robot and tested models).
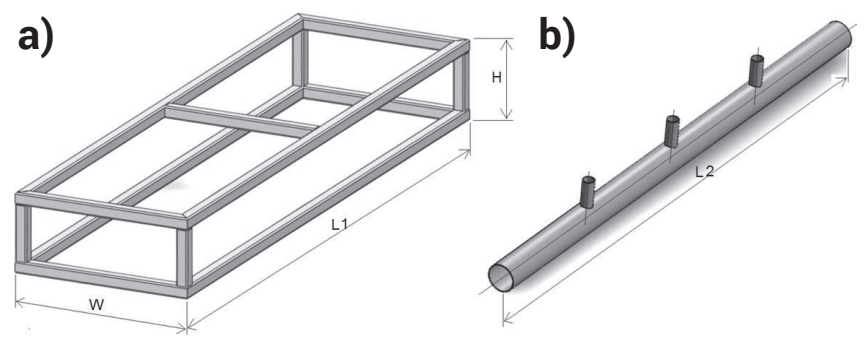

Fig. 9. Some examples of work structure models to be manipulated with the use of tested manipulators: a) frame, b) pipe ( $\varnothing 200 \mathrm{~mm})$ with stub-pipes ( $\varnothing 85 \mathrm{~mm}$ )

\section{Preliminary analysis of cooperation - static geometrical tests}

First, preliminary geometrical tests were carried out to check the correctness of interaction between robot workspace and base models of positioners and runways. Workspaces of selected robots with maximum spaces of the manipulators examined (in accordance with Table III), including also with the developed models of manipulation objects (Fig. 9), were put together in a way that maximizes the common area, reflecting the ability to operate the robot against potential loading. The analysis was visual - 3D views and flat projections of subsequent combinations were observed (Fig. 10 and 11).

As can be seen in Figure 10, a welding robot with an extended arm fixed on a small elevation is theoretically able to handle the loading of the ' $\mathrm{H}$ ' spindle positioner with a four meter disk spacing. Rotation of the object inside the space of the maximum positioner provides access to it from many sides, making it easier to obtain correct welding positions.

On the other hand, the maximum space of the smaller of the developed 'L' positioners is not fully achieved with the robot arm of standard size (Fig. 11a). The use of a $2.5 \mathrm{~m}$ floor runway is not an important convenience in this case. Only the use of the movable axis of the positioner - the rotation of the ' $L$ ' arm and the working table, will allow to reach the previously unreachable areas with an effector (Fig. 11b). There is no guarantee that the correct welding positions will be obtained

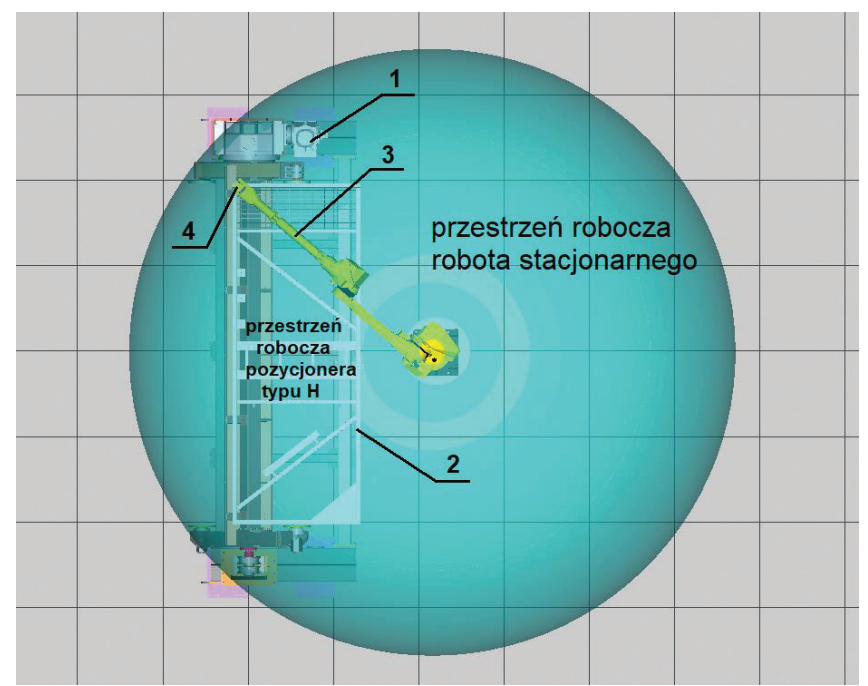

Fig. 10. The static geometric test - impositioning of both working range of robot $(710 \mathrm{iC} / 20 \mathrm{~L})$ and maximum working range of $\mathrm{H}$-type manipulator. 1) the manipulator, 2) the manipulator maximum working range, 3) the robot arm, 4) the efector end [12] 

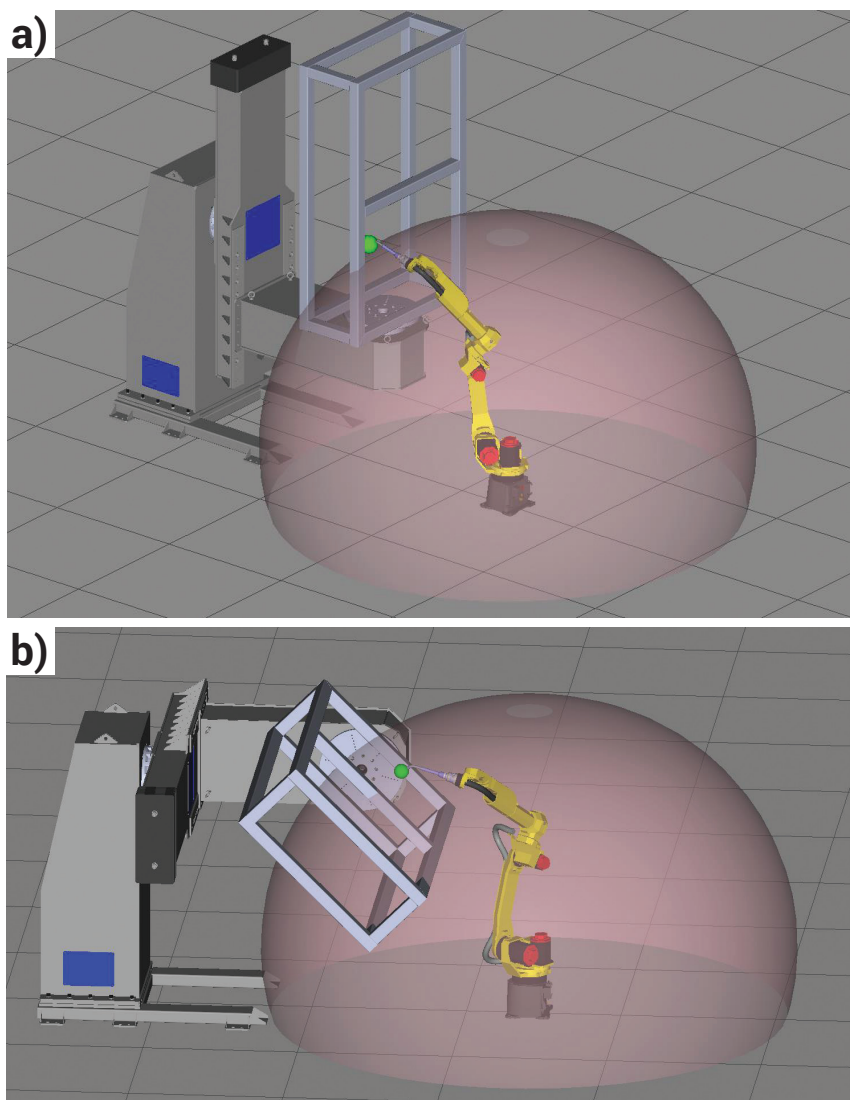

Fig. 11. The static geometric test - impositioning of both working range of standard robot (ArcMate 100iC) and maximum working range of L-type manipulator $(250 \mathrm{~kg})$ [13]

Already at the stage of static tests, some drawbacks of the manipulator models developed were captured. Figure 12 shows the situation in which a horizontal position robot attached to the track motion in the wall position operates against the frame model placed between disks of the ' $\mathrm{H}$ ' positioner. The positioner arm is positioned in a typical, oblique position, facilitating loading on the lowered side. You can see that the robot is mounted too low.

Further, for the tested configurations and comparisons, analyzes and visual verifications of the effective operating range were carried out with provided, at selected points, vertical orientation of the electrode axis of the electrode holder fixed at the end of the robot arm (as for welding in a down position).

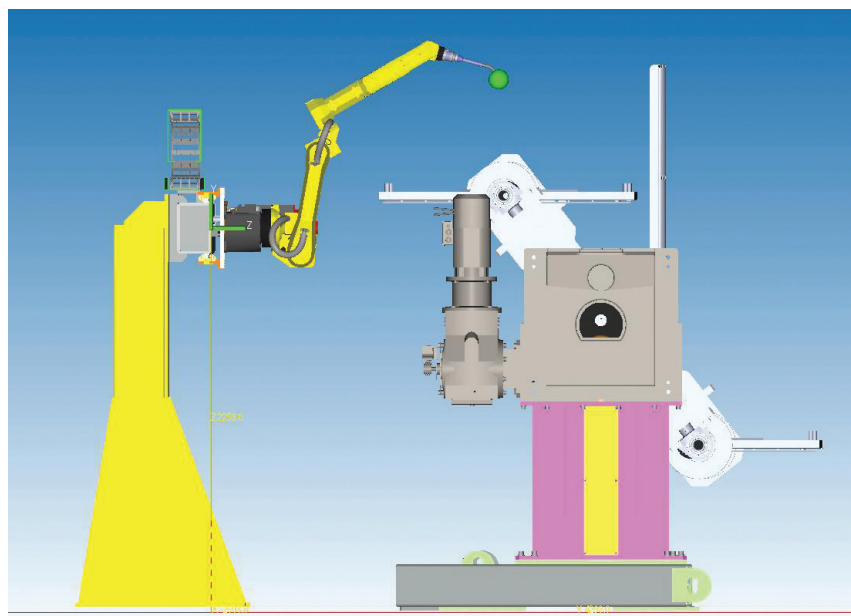

Fig. 12. The static geometric test - cooperation between standard robot (ArcMate 100iC/7L) and the frame model being fixed on $\mathrm{H}$-type manipulator $(1000 \mathrm{~kg})$ [12]
A detailed case study from Figure 12 carried out to ensure the vertical orientation of the electrode confirmed the unsuitability of this configuration. Figure 13 shows how high the robot base should be placed (here with the inverted mounting on the added $L$ boom), in order to reach the bottom position in the corner points of the welded frame model. Of course, in the place of the rising boom on the floor track, a modified runway structure should be used.

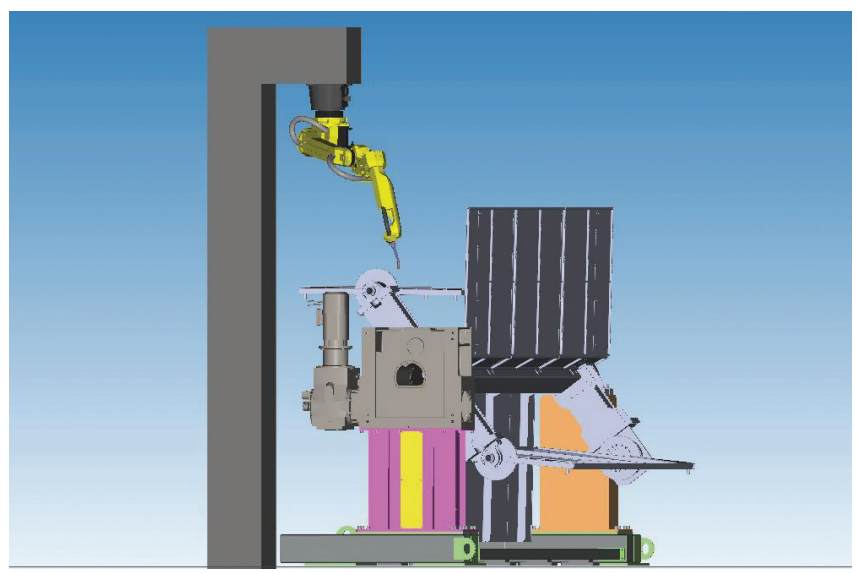

Fig. 13. The detailed geometric test - simulation of proper cooperation between standard robot (ArcMate $100 \mathrm{iC} / 7 \mathrm{~L}$ ) and the frame model being fixed on $\mathrm{H}$-type manipulator (as in fig. 12) with vertical electrode orientation [12]

\section{Movement tests}

The analyzes presented so far were preliminary - static and enabled finding the best settings in the space of the position of selected manipulators and robots (according to Table III). However, they required labor-intensive observations of many views of the same scene, with the manual adjustment of the movable axes of positioners, motion tracks and robots. Next, for the best configurations and settings tested statically, more advanced actions were performed - using the coordinated movement of the robot and the manipulators under study. Their aim was to verify the effective operating range (ability to cooperate) with the vertical orientation of the electrode axis of the electrode holder attached to the end of the robot arm, both at designated points, and a programmed, continuous path between them. Collision risks were analyzed with structural elements of positioners (especially double-stand ones when changing operated sides), errors in motion sequences, missing range, etc.

Figure 14 presents the result of such tests for the configuration from Figure 10 (floor installation of a robot with an extended arm), using a coordinated robot movement and a spindle positioner rotating the welded frame. The motion phases of the robot and the positioner shown in the figure show the possibility of continuously making a butt weld lying on the perimeter of a rectangular tube, ensuring constant vertical orientation of the electrode. After making the first part of the joint (phase 1 in Fig. 14) and reaching the corner, the frame rotates (phase 2) and a smooth transition to the next section of the weld with the changed position of the frame occurs (phase 3 ).

Figure 15 shows the effect of movement tests of the configuration from figure 10, with the robot with an extended arm located on a small base placed on the opposite of the positioner ' $\mathrm{H}$ '. In conditions ensuring vertical orientation of the electrode, there was a risk of collision with manipulated objects. The remedy was to raise the robot. 

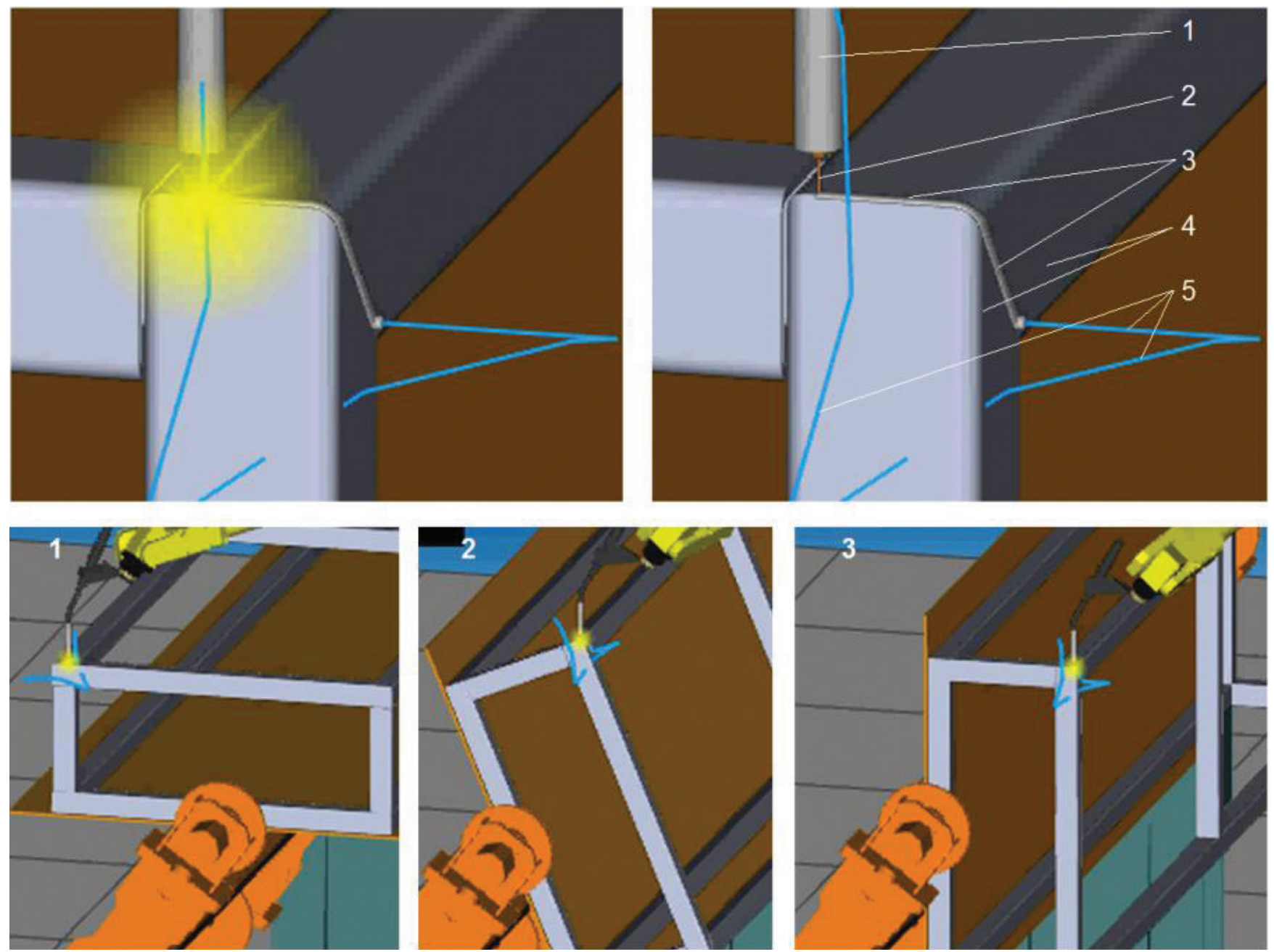

Fig. 14. The coordinated movement of the stand shown in figure 9: 1) MIG/MAG electrode holder, 2) the electrode, 3) the weld (working movement), 4) welded parts, 5) set-up movements [14]

Placing a fixed robot with an extended arm on the opposite of the 'L' positioner $(250 \mathrm{~kg})$ provides, unlike the standard robot (Fig. 11), the possibility of operating freely in the maximum space of the positioner. During motion tests a high collision of such a solution was revealed (Fig. 16). The solution is to put the robot on a short floor runway.

Detailed analysis of the effector movement path is possible via the "CAD-to-path" function built into the ROBGUIDE package. Figure 17 shows an example obtained during the movement of coordinated robot and spindle positioner

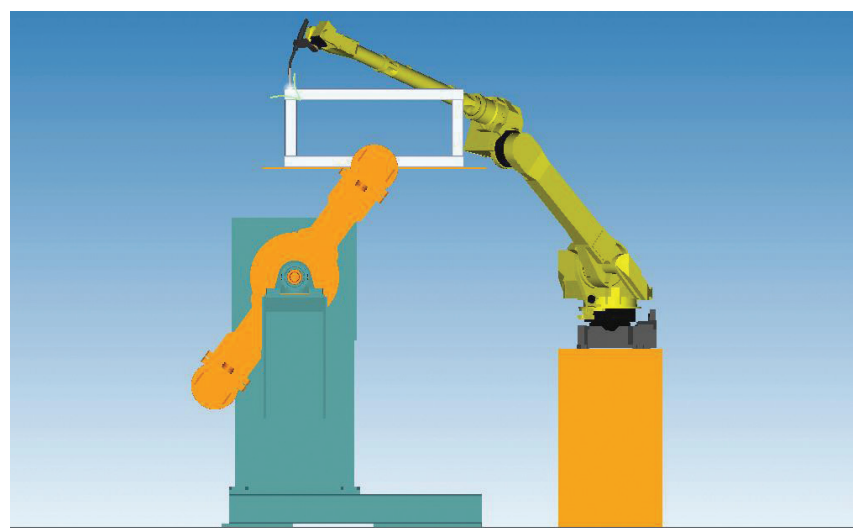

Fig. 15. The collision with the frame being welded due to low base [14]

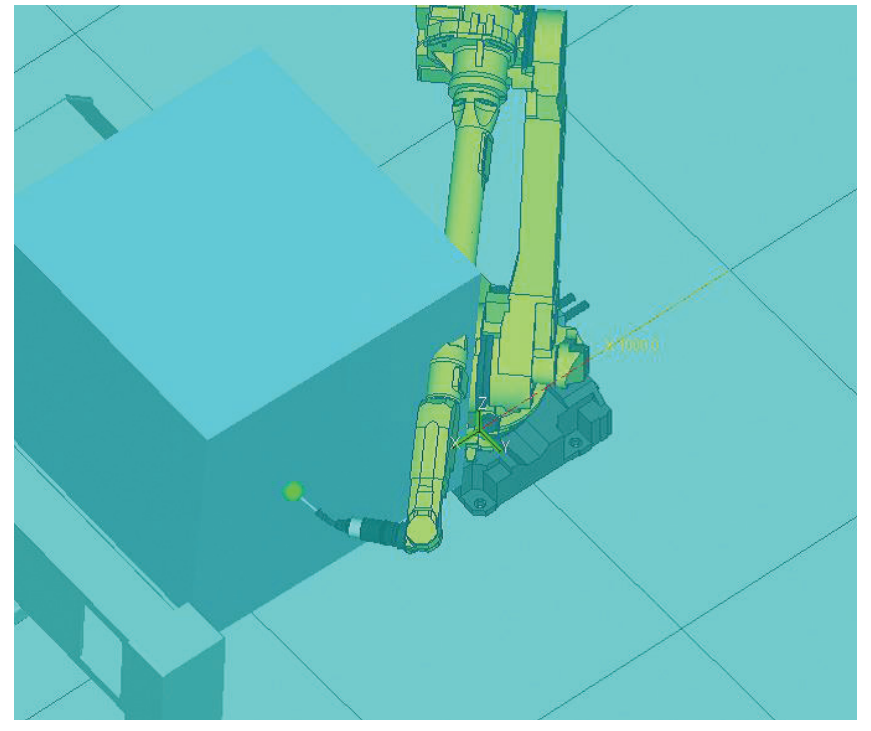

Fig. 16. The collision between motion-free robot with elongated arm and L-type manipulator $(250 \mathrm{~kg})$ working range [15]

of ' $\mathrm{H}$ ' type with attached pipe model with stub pipes. It has become possible to accurately determine and follow the trajectory of the effector's movement (Fig. 17a) or to show the change in the angular orientation of the axis of the indicated element (Fig. 17b). 

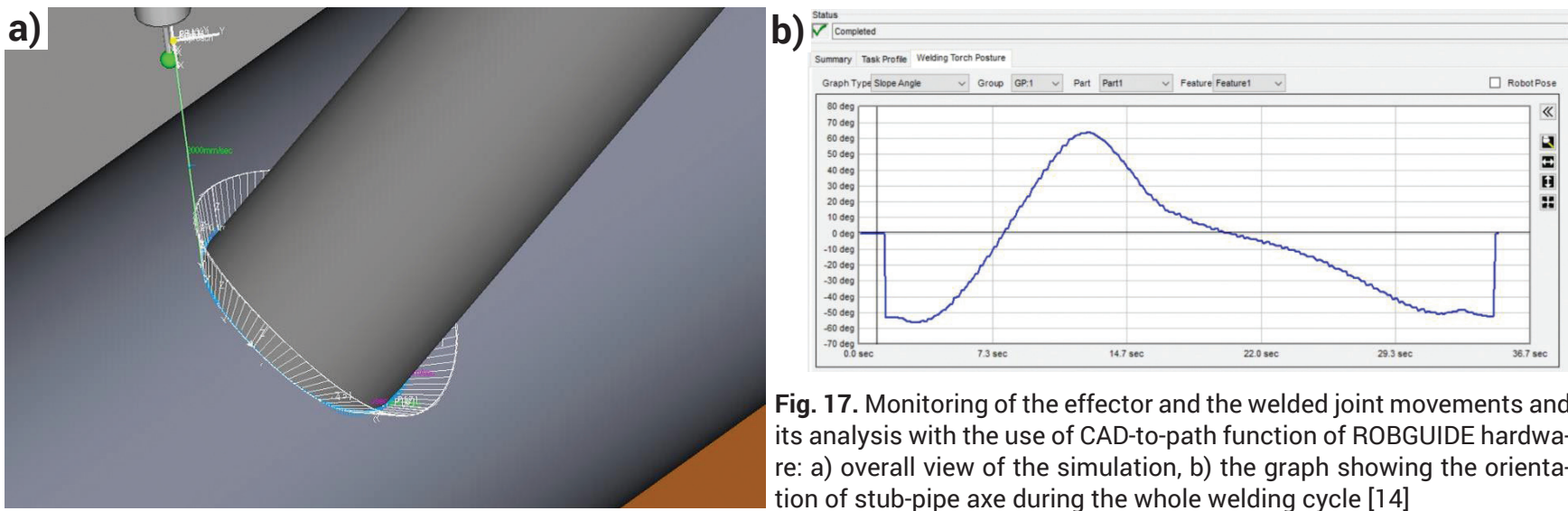

Fig. 17. Monitoring of the effector and the welded joint movements and its analysis with the use of CAD-to-path function of ROBGUIDE hardware: a) overall view of the simulation, b) the graph showing the orientation of stub-pipe axe during the whole welding cycle [14]

\section{Summary and Conclusions}

An example of the effective use of off-line simulation for the verification of construction models of CAD positioners and the modular system of motion tracks may be the solution to the problem of too low position of the gantry runway beam depicted in Figure 12. In this case, the robot should be mounted in an inverted position, respectively high (Fig. 13). Another method (Fig. 18) can be fixing the same standing robot (Fanuc Arc Mate 100iC/7L) to the substrate via a rising base (up to approx. $2500 \mathrm{~mm}$ ). The presented solution ensures correct welding conditions at about half the length of the frame. This type of off-line simulation allows you to get information about the required height for a standing robot. A further effect of the conducted analysis is the proposal to replace the elevation of the track, with a new variant of the track, using standard poles, but with a horizontally mounted running beam and passing the robot in a standing position (Fig. 19).

It can be seen that at the stage of design research of new types of manipulators it is rational, in addition to the performance and analysis of CAD construction models and their FEM strength calculations, to carry out virtual movement tests in an off-line environment. This will eliminate the need to build real, expensive models, accelerating the development and construction of prototypes. Only the phase of final prototype movement tests will entail significant costs, but it will be the final, reliable confirmation of the quality of the adopted solutions.

The work was carried out as part of the project no POIR.01.01.01-00-0271/16, 2014-2020

The National Centre for Research and Development

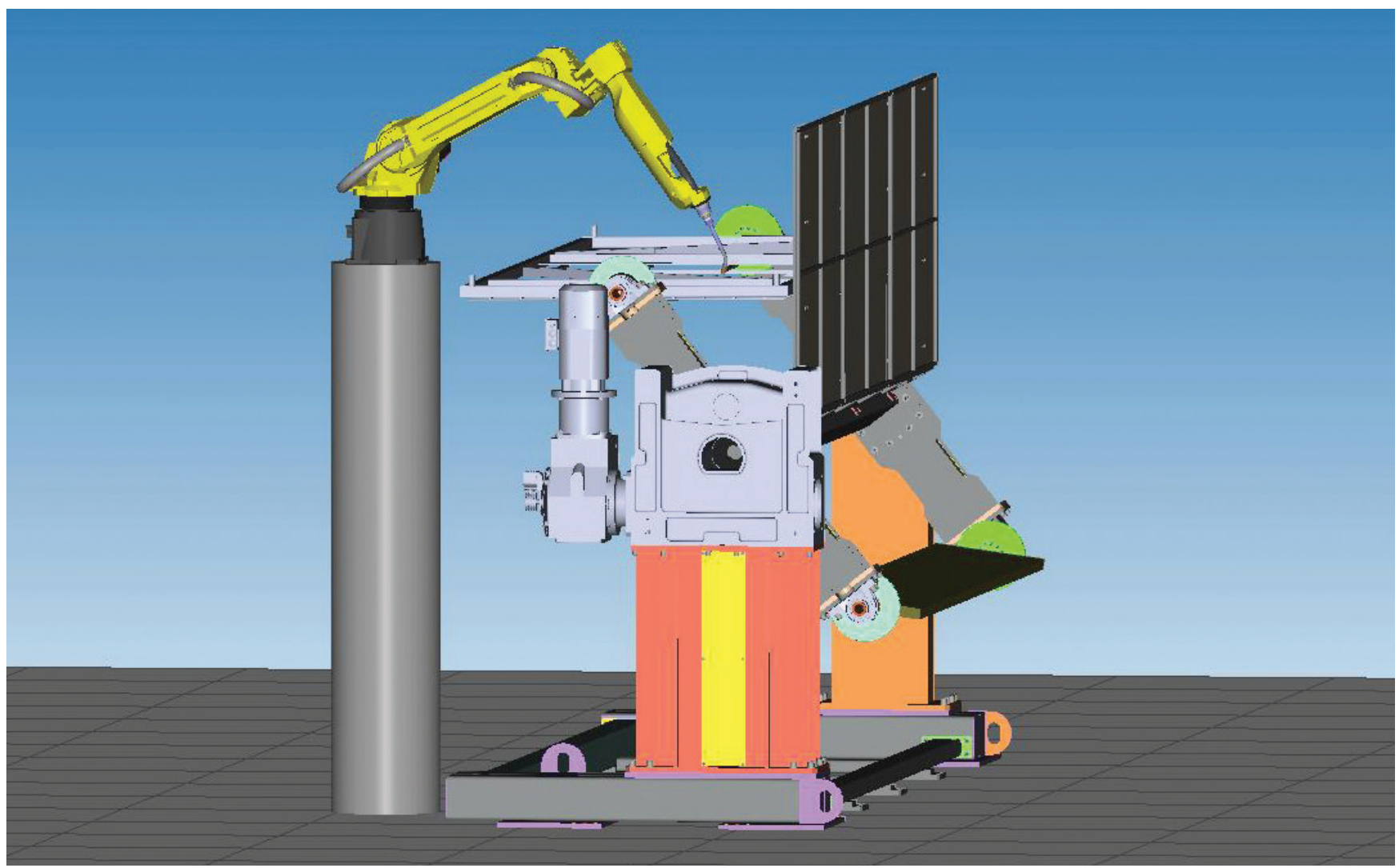

Fig. 18. Simulation of rising the robot fixed in standing position [12] 


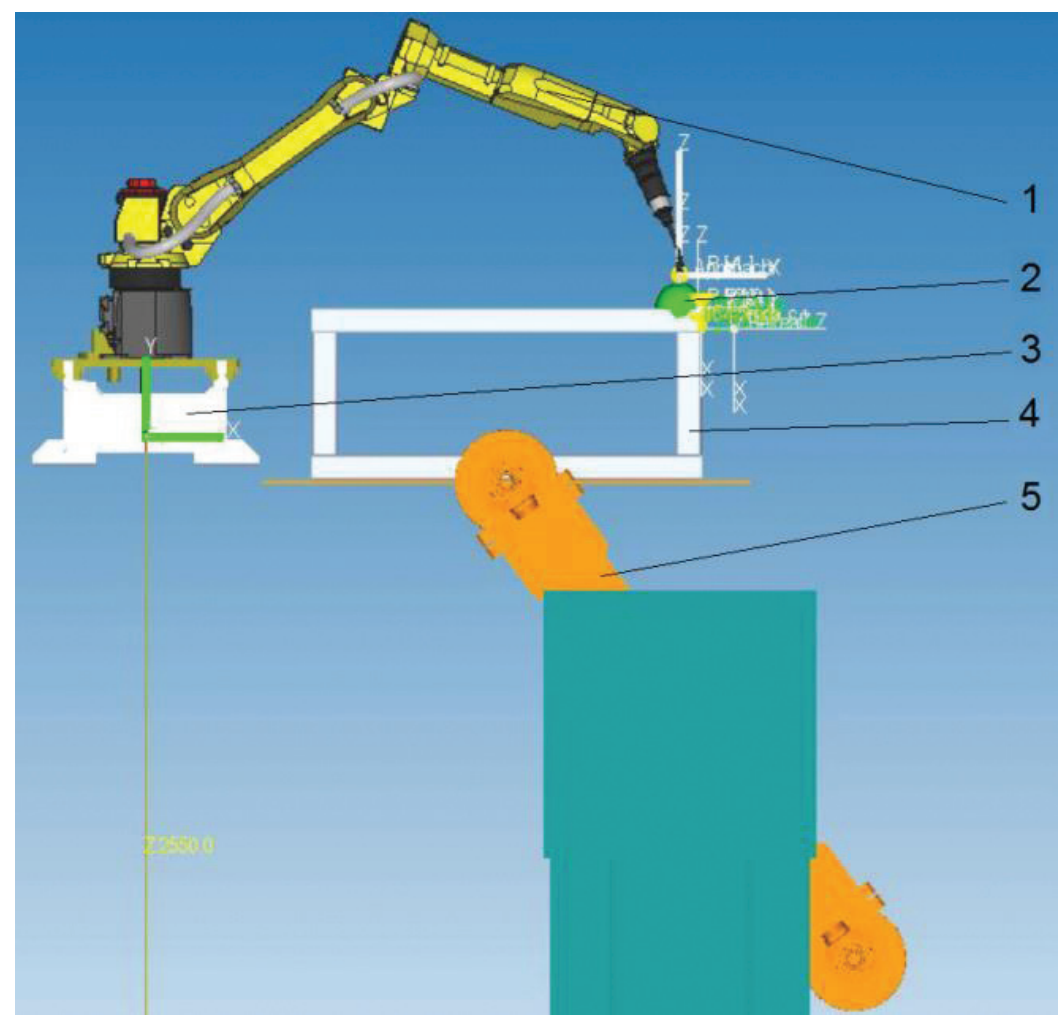

Fig. 19. Simulation of a new version of gate motion track and robot movement in standing position: 1) the robot arm, 2) the efector end, 3) the gate track, 4) frame model, 5) ' $H$ ' positioner [14]

\section{References}

[1] G.S. Bolmsjo, A kinematic description of a positioner and its application in arc welding robots, Automated and Robotic Welding 11 (1987).

[2] P. Cegielski, Automatyzacja i robotyka w budowie maszyn. Skrypt Politechniki Warszawskiej, Tempus (1997).

[3] P. Cegielski, Wybrane aspekty orientacji przestrzennej głowicy roboczej podczas zmechanizowanego i zautomatyzowanego spawania łukowego, Welding Technology Review (2016), vol. 88 (2), 35-40.

[4] P. Cegielski, D. Golański, P. Kołodziejczak, A. Kolasa, D. Rochalski, Weryfikacja modeli konstrukcyjnych pozycjonerów spawalniczych w oparciu o modelowanie matematyczne MES, Welding Technology Review (2018), vol. 90 (1), 36-42.

[5] P. Cegielski, D. Golański, P. Kołodziejczak, A. Kolasa, T. Sarnowski, Studium rozwiązań konstrukcyjnych nowej generacji zewnętrznych osi robotów przemysłowych, Welding Technology Review (2017), vol. 89 (11), 84-92.

[6] P. Cegielski, A. Kolasa, T. Sarnowski, Nowe konstrukcje pozycjonerów jako zewnętrznych osi robotów przemysłowych, Welding Technology Review (2016), vol. 88 (1), 27-32.

[7] G. Herden, Schweisroboter. VEB Verlag Technik Berlin, Edycja Maszinostrojenie, Moskwa 1988.

[8] J. Honczarenko, Roboty przemysłowe. Budowa i zastosowanie, WNT Warszawa, 2011
[9] W. Kaczmarek, I. Jużak, Projekt zrobotyzowanego stanowiska do spawania kolan rur preizolowanych o różnej średnicy, Biuletyn WAT (2012), vol. LXI (1), 259-277.

[10] J. Knapczyk, P.A. Lebiediew, Teoria mechanizmów przestrzennych i manipulatorów WNT, Warszawa (1990).

[11] V. Malin, Designer's guide to effectiwe welding automation - part I: analysis of welding operations as objects for automation, Welding Journal 11 (1985).

[12] V.L. Jr Mangold, Robotic arc welding system design, Welding Journal 11 (1989).

[13] A. Pashkevich, A. Dolgui, Kinematic Control of A Robot-Positioner System for Arc Welding Application. Industrial Robotics: Programming, Simulation and Application, ISBN 3-86611-286-6, ARS/pIV, Germany, December (2006), 702, Edited by: Low Kin Huat.

[14] M. Panas, Analiza technologiczna pozycjonerów spawalniczych na drodze symulacji off-line, Praca dyplomowa inżynierska, kierujący dr inż. P. Cegielski (2018).

[15] M. Tomaszewski, Analiza funkcjonalna zewnętrznych osi robotów przemysłowych na drodze symulacji off-line, Praca dyplomowa inżynierska, kierujący dr inż. P. Cegielski, 2018.

[16] J. Wróbel, Technika komputerowa dla mechaników, PWN, Warszawa (1994). 